\title{
The Most Common Primary School Pupils' Misconceptions Based on the Concept of Protection in the Chemical Context
}

\author{
Monika Šindelková*1a and Irena Plucková ${ }^{2 b}$ \\ ${ }^{1}$ Masaryk University Brno, Faculty of education, Pořící 7 Czech Republic \\ ${ }^{21}$ Masaryk University Brno, Faculty of education, Poříčí 7 Czech Republic \\ E-mail address: ${ }^{a}$ sindelkova.monika@seznam.cz, ${ }^{b}$ Pluckova@seznam.cz
}

Keywords: misconception, wrong idea, concept, pupil's idea, teaching, concept map, concept of protection

\begin{abstract}
Each pupil brings from his/her everyday life a lot of personal experiences and ideas. These ideas about various concepts and topics can sometimes be mistaken or completely wrong. A complex term misconception is used for a summary of these mistaken ideas. Misconception is seen as a wrong notion, wrong idea. It occurs in the context of the pupil's mistaken notions and mistaken conception of the curriculum or one of the forms of pupils' conception of the curriculum. In the course of teaching, pupils are affected not only by teachers, but also by pupil's ideas and experiences that pupils bring from their surroundings. Teachers should be able to work with these ideas and try to correct pupils' misconceptions. A part of this contribution is not only a literature review of the misconception issue, but mainly the results of a research carried out on pupils in the eighth and ninth grades in nine primary schools. The aim of the research was mapping the most common misconceptions associated with the concept of protection in the chemical context of the curriculum.
\end{abstract}

\section{INTRODUCTION}

We meet with a large amount of information in everyday life. This information is influenced by the environment and social culture in which we live. No wonder that every individual has their own supply of concepts, images, ideas or knowledge. Unfortunately, such information, ideas and concepts are not always accurate, error-free or complete. In most cases, wrong ideas (misconceptions) prevail. The educational process has the major task to correct such misconceptions and wrong concepts. To try working with them in order to correct them and after that fix them for a long time. This task is not simple and to fulfill it properly, it is necessary for teachers to familiarize with the most common misconceptions of their students. They can choose, for example, a conceptual change theory. This theory can, in a metaphorical sense, help with selecting an appropriate form and didactic method for teaching in individual lessons.

The conceptual change theory is built on the premise that knowledge cannot be simply passed, but it is necessary to build it from the inside. The term conceptual change is used in the literature both for the processes that change children's concepts and the theory of these processes. Dvořáková [13] points out a common feature of the conceptual change theory in her study, which is an emphasis on a domain-specific research of the children's thinking development. Unlike the Piaget's direction to general stages of children's thinking, the conceptual change is assumed that the cognitive development of various areas of reality may proceed at a different pace and has its own specific problems. Both perspectives respect the premise of domain specificity and are identical in that conceptual cognition is very influenced by everyday experience, and they also deal with the role of systematic schooling. Child's experiences are the basis of causal explanations, which also affect subsequent formal (school) learning, although they are often incompatible with the content of the school curriculum.

Teachers may be surprised that despite the great effort the pupils may not understand the basic concepts that are related to specific topics. Sometimes it happens that pupils learn only by 
memorizing presented information and facts, but they completely miss a subsequent interconnection with other themes. Even this may be a cause of formation of various misconceptions. They then lead to other possible complications during the learning process.

The aim of this research was to identify the most common misconceptions based on the concept of protection in the chemical concept of curriculum. The term "protection" was chosen because of the complexity and interconnection with all humanities and natural science subjects and personal life of each individual.

\section{MISCONCEPTION}

Misconception is explained in many publications as a wrong idea accompanying a daily life of the individual. Professor Ceken [1] states that misconceptions can be determined as thoughts that give a wrong understanding of certain ideas, knowledge or processes. These ideas are exclusively based on personal experiences of the individual (on his naive theories, scientific assumptions, various terms or concepts). Thompson [5] claims that students may have strong ideas and concepts of various natural phenomena from their personal daily lives that affect their understanding during a science experiment demonstration in teaching process. Subsequent explanation and description of demonstrated scientific phenomena is therefore a difficult task for the teacher. It is often quite demanding even from the perspective of pupils who have to make their existing ideas more specific or completely transform them. Hanuscin [3] calls misconceptions a conceptual misunderstanding that pupils gain during daily activities and especially from sources other than science education. These conceptual misunderstandings arise when students study a science text only by method of memorizing and they do not try to understand the topic or connect it with already fixed knowledge. Dealing with these wrong models of certain natural phenomena is usually quite difficult for pupils and in most cases their correction is completely impossible.

Committee on Undergraduate Science Education [4] categorizes misconceptions into four groups, each associated with an educational process:

- Biases - represent such misconceptions that pupils receive from various non-scientific sources, such as religion and their own beliefs.

- Conceptual Misunderstanding - these misconceptions arise during the actual teaching of a particular topic, while there is an incomplete explanation of an issue, e.g. due to communication noise between teacher and student.

- Dialect Misconceptions - these are misconceptions stemming from the influence of improper use of phrases to describe a particular phenomenon (in most cases very specialized terms or obsolete phrases).

- Factual Misconceptions - these are misconceptions arising at an early pupils' age and accompanying them until their adulthood.

In one of his works dealing with mathematical algebra. Clement [2] states that the basic form misconception is not in a bad approach of information by a student during the learning process, but it is rooted deep in his mind from an early age. Remedy of misconceptions is possible from the perspective of mathematics if teachers learn to use word problems or phrases in the teaching of various topics.

Doulík and Škoda [12], deal with the issue of misconceptions and especially preconceptions in the Czech Republic. Both authors are recognized experts in their field. Doulík and Škoda [12] also point out to a greater or lesser diversity of various names for the individual characteristics of the concepts misconception and preconception. They consider especially the term misconception to be rather inappropriate, because an error is included in its meaning, whereas ideas on a given concept do not always have to be wrong. They can be right, but only under predetermined and defined conditions. 
Vyskočilová and Dvořák [15] emphasize that it is often advantageous to use neutral terms to describe the aforementioned phenomenon, because they do not include a clear indication that the student idea is wrong. Therefore they recommend terms such as children's interpretations of the world or existing concept. It does not mean that the term of misconception would be considered bad, but the above-mentioned authors understand them rather in more specific and concrete connections. In the traditional concept of education, pupils' preconceptions are taken mostly as misconceptions. The term "misconception" is usually understood negatively, because they are preconceptions that are in terms of current scientific knowledge wrong (but not in terms of individual knowledge of the child itself).

A publication of the author Jelemenská [14] is undoubtedly interesting and beneficial from the point of view of this text. It deals with the concepts of pupils (whether preconceptions or misconceptions) from the perspective of educational reconstruction. This theory is based on constructivism and it is a means of systematic research of field education and reflection on teaching and learning. It has three phases - clarification of field ideas, research of pupils' ideas and didactic structuring the learning environment. The researches implemented according to the research framework of didactic reconstruction show in various content areas that the pupils' ideas and scientific ideas show common characteristics.

Naive ideas of pupils may be right and wrong. These ideas relate to a certain area of the fact given, which means that they can be in contradiction to the ideas that the same person created to other areas. From this view, ideas are also seen as default domain specific theories [5].

\section{CONCEPT MAPPING RESEARCH METHOD}

Another method by which it is possible to examine the issue of preconceptions and misconceptions is called concept mapping. It is a very old technique used by some great creative personalities, such as Leonardo da Vinci and Albert Einstein. According to Buzan [6], concept maps are a revolutionary way to create notes, which offers a way to better learning and understanding the context of the given issue. They are presented as the "best tool" for thinking. They are graphically processed imitation of the processes in the brain and are designed so that the brain uses the maximum of its abilities.

The use of concept maps in research investigations is very common today. Many authors use a so-called triangulation method to raise the validity of performed research examination. With the help of several methods together, we get a variety of information and perspectives to a research problem. Triangulation involves drawing, oral expression and written expression (the method of concept map is used here). The methods triangulation was not used in this research. This is only an outline of the most commonly used method associated with concept maps. The subject of this research includes only the method of concept map. In other related researches, the authors would like to compare the difference between the research carried out only with the help of concept maps and the research that would also use drawings and oral expression besides concept maps, i.e. the aforementioned triangulation.

Concept mapping is most used in educational techniques for improving understanding. It is an expression of relationships between concepts and their graphic form. Concepts are represented in concept maps as marked graph elements and concept relationships as connecting lines that mark themselves. Concept maps are made up of words, concepts and ideas and facilitate orientation in the mind of the individual. Many authors call them mental or mind maps. The mind maps are used to represent and distribute one particular main topic, the concept maps are used to capture a concept as such and therefore are not restricted to one particular topic, because of thinking about a particular problem or solution to a given problem. We used them to show various phenomena associated with thinking and creating concepts and technical terms.

Spousta [10] states that we can use a concept (mental) map to schematically represent objects, phenomena, mutual relations, links, connections and even a structure of an object. It is a unique 
gnoseological tool that can capture typological aspects of abstract thinking. Such concept maps are capable of giving a form and symbolism to concept system. They provide, among other things, means to express ideas, stimulate active thinking, develop cognitive skills of analysis, synthesis, classification, generalization and facilitate orientation in an issue. Individuality and uniqueness of a created structure facilitate to remember and subsequently recall it. It mainly draws attention to thinking processes to which it is possible to go back and think again about the discussed issue. Concept maps belong to the qualitative method of research. Concept maps illustrate the links between concepts. Concept mapping is associated with a structural element of the child's conception. This method is also suitable for lower age group of children.

According to Buzan [6], the mental (concept) map:

- activates the entire brain, deprive our mind of a mental disorder,

- allows us to fully concentrate on a particular subject, clearly demonstrates the connection between isolated information,

- clearly captures both the details and the whole, allows us to combine or vice versa separate individual ideas and mutually compare them,

- requires full concentration on the subject of our interest - thanks to that a given information is transferred from our short-term memory into long-term memory.

The concept of "Protection" is associated with the following:

- The protection of intellectual property rights, copyright and information sources.

- The legal protection of citizens and the protection of personal property rights of individuals and society.

- The protection of nature, environment, plants, animals and other species.

- The protection of human rights of individuals.

- The protection of man in situations threatening health and life (natural disasters, behavior during natural disasters).

- The protection from non-communicable and communicable diseases and chronic illness.

- The protection of individuals (pupils) against bullying, violence and other pathological phenomena.

- The protection in connection with the work safety of individuals (pupils), the protection against accidents.

- The protection of health while performing different activities (e.g. an experiment).

- The protection of man against radiation.

The subject of chemistry can be certainly connected with the points no. 5, 8, 9 and 10 together. And not only with the implementation and demonstration of pupil experiments, but especially with the performing of various laboratory exercises that are typical for the subject of chemistry. During them, pupils are constantly warned of the importance of following the basic safety precautions when working with chemicals. The work safety and therefore also the protection of pupils' health in the conducting of chemical experiments is the basic condition for the smooth running not only of chemistry lessons but also other science subjects. 


\section{THE RESEARCH DEALING WITH THE MOST COMMON MISCONCEPTIONS ASSOCIATED WITH THE CONCEPT OF PROTECTION IN THE CHEMICAL CONTEXT}

The research of the most common misconceptions associated with the term "protection in the chemical context" included the use of a qualitative research method - a concept map. The research was compiled on the basis of the Framework Educational Programme for Primary Schools, updated in 2013, which determines a mandatory content of the curriculum in natural sciences (chemistry in our case). The concept of "protection" in the chemical context is mentioned in connection with the conducting of various chemical experiments and the safety and security of the population in emergencies (chemical spills, fires, natural disasters - flood, radiation accident, etc.).

The research involved 116 pupils of the eighth grade from six primary schools in the South Moravian region. The research was conducted at the beginning of calendar year 2015 (February March). The primary schools were of urban type. The research was of transversal nature. The classes of eighth grade pupils from six primary schools were chosen based on their comparable average scores evaluated in the first half of the school year 2014/2015 in the subject of chemistry.

The conducted research was to aimed to find out what are the most common pupils' misconceptions associated with the concept of "protection" in the chemical context. The research method of the conceptual map was used as a diagnostic tool. It was a qualitative research in which the following research problems were determined.

The major research problem:

Pupils distinguish the concept of "protection" from the perspective of chemical context and define its essential role in protecting health in when conducting chemical experiments.

Partial research problems:

How do pupils distinguish the concept of "protection" in the chemical context?

How do pupils define the concept "protection" in relation to protecting health when conducting chemical experiments?

\section{RESULTS OF CONDUCTED RESEARCH}

During February 2015, eighth grade pupils of primary schools got blank A4 sheets on which they were supposed to create a concept map that represented the first associations related to the concept of "protection" in the chemical context. Each pupil created their own concept map in which there is obvious a connection of the concepts with the key concept of "protection".

All concepts and phrases presented by the pupils in the concept maps were sorted out and classified by the authors. Each term the pupils presented was explored and defined as a misconception or preconception in accordance with predetermined conditions based on curriculum documents for primary schools. The presented research deals only with the misconceptions that are determined according to the above-mentioned conditions. The table 1 contains an evaluation of the pupils' concepts appeared in their concept maps. This is a percentage representation of individual concepts (misconceptions).

A majority of 116 questioned respondents connected the concept of "protection" in the chemical context, but also a lot of concepts that are not related to the concept of "protection" in the chemical context appeared. Although they are related with this concept, but unfortunately not in the researched chemical context. In most cases, it is a connection of the concept with information from humanities subjects (such as civics, health education, etc.) and with daily lives of the pupils.

The most common misconception appeared in the conducted research is the concept of "condom", the pupils put it into their concept maps in more than $30 \%$ of the total represented misconceptions. This is due to a great effort of various non-profit institutions as well as large corporations to draw attention to possible negative effects of unprotected sexual intercourse among underage students. Most primary schools regularly hold seminars dealing with safe sex and sexually 
transmitted diseases. These seminars are organized under the auspices of various non-profit and advisory centers. The notional second place in the list of the most often misconceptions is divided into two terms in the percentage of $20.7 \%$ - the terms of helmet and sunglasses. The helmet is a general term, which has a lot of types according to activity for which it is designed for. In their everyday lives, the pupils meet at least the types of helmets designed to protect them against injury while participating in various sports activities (biking, horse riding, roller skating, skiing, mountaineering, etc.). The helmet is also a protection that is used by rescuers when eliminating emergencies. Here you can see the effect of newly implemented topics from the field of safety and protection of people in emergencies. The term "sunscreen" with the percentage of $14.4 \%$ is connected with increasing awareness of pupils about the risks associated with sunlight and protection against its negative effects. The term "weapon" appeared with the percentage of $8.6 \%$. The weapon is a tool using to promote individuals' interests and to protect individuals' material and spiritual values and health. Most commonly it is used for the purpose of causing injury to a living organism. In recent years, we have met with weapons at schools more and more often. All educational institutions strictly prohibit to possess weapons in their buildings and the violation of this is strictly punished. The pupils meets with attacks by pupils on teachers and classmates in the media. This emerging phenomenon has become a major problem. Educational institutions are trying to protect the health of all individuals occurring in their buildings. The term "fire extinguisher" appeared with the percentage of $3.7 \%$. It is the most commonly used material means of protection against fire. It has to always be placed on a freely accessible place in buildings or vehicles and its serviceability is inspected by a competent national authority. Using a fire extinguisher in an emergency can save lives and reduce property damage to property.

Table 1: The Most Common Primary School Pupils' Misconceptions Based on the Concept of Protection in the Chemical Context

\begin{tabular}{|l|l|}
\hline Term & Percentage of pupils \\
\hline Sunglasses & $20.7 \%$ \\
\hline Weapon & $8.6 \%$ \\
\hline Condom & $31.9 \%$ \\
\hline Helmet & $20.7 \%$ \\
\hline Sunscreen & $14.4 \%$ \\
\hline Fire extinguisher & $3.7 \%$ \\
\hline
\end{tabular}

\section{DISCUSSION AND CONCLUSIONS OF THE CONDUCTED RESEARCH}

The conducted research included diagnostics of the most common primary school pupils' misconceptions based on the concept of "protection" in the chemical context. The qualitative method of concept maps was chosen for determining the most common misconceptions. The research included 116 eighth grade pupils from six primary schools in the South Moravian region and it was conducted in February and March 2015. Subsequently, the concept maps were evaluated and processed.

The findings and conclusions acquired from the evaluation of the research are very diverse. From the diagnosed concepts, the "condom", "sunglasses" and "helmet" showed to be misconceptions. They were wrong ideas associated with the concept of "protection" in the chemical context. The concepts found in the research may be associated with the concept "protection", but just in case of determining different research questions and conditions. The research monitored the chemical context of the concept of "protection" and was also implemented in chemistry lessons. Pupils' misconceptions can be diagnosed by using many research methods, in the case of this research the use of concept maps proved to be the best. 
Extracurricular leisure activities affect the perception of the majority of concepts that pupils encounter in classes in all school subjects. The conducted research shows that some associations connected with the specified concepts have extracurricular origin (the term "weapon" appeared at $8.6 \%$, "condom" at $31.9 \%$ or "extinguisher" at $3.7 \%$ ). Nowadays, the pupils are overwhelmed with a lot of information that comes from various sources of information, such as the Internet, media or means of telecommunication. And we cannot ignore daily school lessons, in which pupils acquire an infinite amount of information from many different fields. Also extracurricular leisure activities are great source misconceptions. Pupils encounter a lot of information that is not considered to be correct or complete, acquire an infinite amount of half-truths, nonsense or even fabrications. These misconceptions are dangerous from the perspective of a long-term fixing in the mind of an individual and, in some cases, of complete absence of their correcting.

\section{CONCLUSION}

The main research issue that "The pupils distinguish the concept "protection" from the perspective of chemical context and define its essential role in protecting the health when conducting chemical experiments" was confirmed only partially according to the results of the above mentioned research. The pupils presented mainly concepts of general nature and related only to protection of human health. The research also included two other sub-goals. Both of them were met.

Diagnostics of the most common misconceptions enables to make teaching process better and more individual. Its added value also includes a selection of appropriate teaching methods and forms. The aim of education process is specifying and improving the acquired misconceptions and put them right for better fixing and subsequently according with reality.

As well as science works, it is necessary for teachers to be able to work with the pupils' misconceptions. Idea (concept) is the cornerstone of education process (as well as science), everything else is derived from it.

\section{References}

[1] CEKEN, Ramazan, 2014. Primary school teacher education students' misconception on waste. International Journal of Academic Research [online]. 6(3): 19-23 [cit. 2015-06-30]. ISSN 20754124. DOI: 10.7813/2075-4124.2014/6-3/B.3.

[2] CLEMENT, John, 1982. Algebra Word Problem Solutions: Thought Processes Underlying Common Misconception. Journal for Research in Mathematics Education [online]. 13(1): 16-30 [cit. 2015-06-30]. ISSN 00218251. http://ac.els-cdn.com/S0732312313000606/1-s2.0S0732312313000606-main.pdf?_tid=2a9ced58-2f82-11e5-8e44 00000aab0f27\&acdnat=1437467361_1f3fe8b249392e82d81f028c83a0b341.

[3] HANUSCIN, Deborah L, 2013. Critical Incidents in the Development of Pedagogical Content Knowledge for Teaching the Nature of Science: A Prospective Elementary Teacher's Journey. Journal of Science Teacher Education[online]. 24(6): 933-956 [cit. 2015-06-30]. ISSN 1046560x. DOI: 10.1007/s10972-013-9341-4.

[4] NATIONAL ACADEMY OF SCIENCES - NATIONAL RESEARCH COUNCIL, Washington. Science Teaching Reconsidered: A Handbook [online]. 1997 [cit. 2015-06-30]. ISBN 0309054982. ISSN ERICRIE0. http://ezproxy.muni.cz/login?url=http://search.ebscohost.com/ login.aspx?direct=true \&AuthType $=$ ip, cookie, uid $\& \mathrm{db}=$ nlebk\&AN=1202\&lang $=$ cs\&site=edslive\&scope $=$ site\&ebv $=$ EB\&ppid $=$ pp_Cover 
[5] SANDER, Elke, 2006. Towards a better understanding of ecology. Journal of Biological Education (Society of Biology) [online]. 40(3): 119-123 [cit. 2015-07-03]. ISSN 00219266. http://ezproxy.muni.cz/login?url=http://search.ebscohost.com/login.aspx?direct=true\&AuthTyp $\mathrm{e}=\mathrm{ip}$, cookie, $u i d \& \mathrm{db}=\mathrm{a} 9 \mathrm{~h} \& \mathrm{AN}=21160149 \&$ lang $=$ cs\&site $=$ eds-live \&scope $=$ site

[5] THOMPSON, Fiona,2006. An Exploration of Common Student Misconceptions in Science. International Education Journal [online]. 7(4): 553-559 [cit. 2015-06-30]. ISSN 14431475.

[6] BUZAN, Tony, 2014. Mental Mapping. 2. ed. Prague: Portal, 165 p. ISBN 978-80-262-0520-3.

[7] JANAS, Josef, 2005. Specific didactic of physic. 1. ed. Brno: Masaryk University, 93 p. ISBN 8021036249.

[8] MANDIKOVA, Dana, 2011. Student's preconceptions in physics. Brno: Paido, 245 p. ISBN 9788073152260.

[9] MERTIN, Vaclav, 2012. Methods and procedures for student: Educational Diagnostics. 1. ed. Prague: Wolters Kluwer Czech Republic, 343 p. ISBN 9788073576790.

[10] SPOUSTA, Vladimir, 2007. Visualization: communication phenomena. 1. ed. Brno: Masaryk University, 161 p. ISBN 978-80-210-4420-3.

[11] SVARICEK, Roman, 2007. Qualitative Research in Educational Sciences. 1. ed Prague: Portal, 377 p. ISBN 978-80-7367-313-0.

[12]DOULIK, Pavel, SKODA Jiri, 2003. Reflections on the aspects of constructivist approach to teaching science subjects. In Pedagogicka revue, 55, number. 5, 470-482 p. ISSN 3330-3815.

[13]DVORAKOVA, Michaela, 2013. Diagnose children's concept of prospective teachers. Orbis scholae[online]. 7 (1): 101-117 [cit. 2015-06-30]. ISSN2336-3177.

[14] JELEMENSKA, Patricia, 2009. Research on teaching: thematic areas of research approaches and methods. 1. ed. Brno: Paido, 179 p. ISBN 978-80-7315-180-5.

[15] VYSKOCILOVA, Eva, 2002. Introduction: Teaching as a science and as a tool for teachers. In: Kalhous, Z. Teaching Methodology. Prague: Portal, p. 17-61. ISBN 80-7178-253-X. 